less by the same arguments. In addition, the fraction of $\mathrm{BO}_{4}$ units changes in such a way as to enhance the growth rate as the $\mathrm{PbO}$ content increases, if $\mathrm{BO}_{4}$ is the structural unit necessary for growth. The scarcity of crystallizable species and the lower driving force for crystallization may account for the decreased growth rate observed in the $50.10 \mathrm{~mol} \% \mathrm{PbO}$ melt where the concentration of $\mathrm{BO}_{4}$ units would be less than for the other melts.

\section{Conclusions}

The determination of the temperature dependence of the growth rate of $\mathrm{PbO} \cdot 2 \mathrm{~B}_{2} \mathrm{O}_{3}$ from several melts showed that the growth rate was greatly increased in those melts which contained slightly more than the stoichiometric quantity of $\mathrm{PbO}$. This increase is attributed to the changes in the melt structure which occur in the interfacial region between the melt and the crystal. The concentration of boron atoms in fourfold coordination with oxygen atoms is increased as the PbO content is increased. These structural units are more readily incorporated into the crystal wherein all the boron atoms are in fourfold coordination with oxygen atoms. In addition, the fluidity of the melt increases with greater $\mathrm{PbO}$ concentration and hence the ease with which structural units may be oriented for attachment to the crystal is increased.

\section{Acknowledgment}

The authors thank the staff of the Central Electron Microscope Facility, University of Illinois, for assistance with the scanning electron microscope.

\section{References}

${ }^{2}$ J. P. De Luca, R. J. Eagan, and C. G. Bergeron, "Crystallization of $\mathrm{PbO} \cdot 2 \mathrm{~B}_{2} \mathrm{O}_{3}$ from Its Supercooled Melt," J. Amer. Ceram. Soc., 52 [6] 322-26 (1969).

${ }^{2} \mathrm{D}$. Turnbull and M. H. Cohen; pp. 38-62 in Modern Aspects of the Vitreous State, Vol. 1. Edited by J. D. Mackenzie. Butterworth \& Co. (Publishers) Ltd., London, 1960.

${ }^{3}$ R. L. Tiede, "Improved Apparatus for Rapid Measurement of Viscosity of Glass at High Temperatures," J. Amer. Ceram. Soc., 42 [11] 537-41 (1959).

${ }^{4} \mathrm{~J}$. A Laird and C G. Bergeron "Interface Temperature of a Crystallizing Melt," ibid., 51 [1] 60-61 (1968).

J. M. Ricker, C. G. Bergeron, and R. J. Eagan, "Enthalpy of Fusion of $\mathrm{PbO} \cdot 2 \mathrm{~B}_{2} \mathrm{O}_{3}$," ibid., [7] 410.

${ }^{6}$ R. F. Strickland-Constable, Kinetics and Mechanism of Crystallization; p. 149. Academic Press, London, 1968.

${ }^{7}$ Clarence Zener, "Theory of Growth of Spherical Precipitates from Solid Solution," J. Appl. Phys., 20 [10] 950-53 (1949).

${ }^{8}$ D. R. Stewart and G. E. Rindone, "High-Temperature Energy Relations in Borates: Alkaline-Earth and Lead Borate Compounds and Their Glasses," J. Amer. Ceram. Soc., 46 [12] 593-96 (1963).

${ }^{9}$ (a) H. D. Keith and F. J. Padden, Jr., "Phenomenological Theory of Spherulitic Crystallization," J. Appl. Phys., 34 [8] 2409-21 (1963).

(b) H. D. Keith and F. J. Padden, Jr., "Spherulitic Crystallization from the Melt: II," ibid., 35 [4] 1286-96 (1964).

${ }^{10} \mathrm{P}$. J. Bray, M. Leventhal, and $H$. O. Hooper, "Nuclear Magnetic Resonance Investigations of the Structure of Lead Borate Glasses," Phys. Chem. Glasses, 4 [2] 47-66 (1963).

${ }^{11}$ S. Takeuchi and K. Furukawa, "Structure Analysis of Some Fused Salts and Oxides by X-Ray Diffraction," Met. Soc. Conf., 7, 133-61 (1961).

${ }_{12}$ A. Perioff and S. Block, "Crystal Structure of the Strontium and Lead Tetraborates, $\mathrm{SrO} \cdot 2 \mathrm{~B}_{2} \mathrm{O}_{3}$ and $\mathrm{PbO} \cdot 2 \mathrm{~B}_{2} \mathrm{O}_{*}$ " Acta Crystallogr., 20 [2] 274-79 (1966).

\title{
Deformation and Fracture of MnTe and MnSe-Mn'Te Solid Solutions
}

\author{
PAUL G. RIEWALD* and LAWRENCE H. VAN VLACK \\ Department of Chemical and Metallurgical Engineering, The University of Michigan, Ann Arbor, Michigan 48104
}

\begin{abstract}
Single crystals of MnTe and solid solutions in the system MnSeMnTe were prepared; selected surfaces were indented with either a Vickers or a Knoop microindenter. Information on mechanical behavior was obtained by observation of slip traces and by study of Knoop hardness anisotropy. Hexagonal NiAstype MnTe and MnTe-rich Mn(Te,Se) solid solutions show plastic deformation attributable to $\{10 \overline{1} 2\}$ twinning, basal slip, and pencil glide in $\langle 11 \overline{2} 0\rangle$. Fracture occurs as primary $\{0001\}$ and secondary $\{10 \overline{10}\}$ cleavage. Vickers and Knoop hardnesses were greater on the basal plane than on prism planes. Cubic MnSe-rich Mn(Te,Se) solid solutions show both $\{111\}$ $\langle 110\rangle$ and $\{110\}<1 \overline{10}>$ slip with $\{100\}$ and $\{110\}$ fracture in crushed fragments and around surface indentations. Knoop hardness anisotropy is like that in MnSe. The rate of solid solution hardening is greater than for comparable substitutions of sulfide ions in the MnSe matrix.
\end{abstract}

\section{Introduction and Previous Work}

HE crystallographic deformation mechanisms, fracture
characteristics, and hardness relations for single crystals
of MnTe and single-phase compositions in the system MnSe-
MnTe were studied in the present work as a continuation of a study of the mechanical behavior of $\mathrm{Mn}$ (Group VI) solid solution compounds.

The stable forms of $\mathrm{MnO}, \mathrm{MnS}$, and $\mathrm{MnSe}$ have the fcc $\mathrm{NaCl}-$ type structure. In contrast, at normal temperatures MnTe has the hexagonal NiAs-type structure with a $c / a$ ratio of 1.621 . The $\mathrm{NaCl}$ and NiAs structures differ in the stacking of anion and cation layers. For the $\mathrm{NaCl}$ structure, the sequence is $A c B a C b A c B .$. along $\langle 111\rangle$, whereas for the NiAs structure it is $A C B C A C B C .$. along $<0001>$. The capital letters represent anion layers and the lower case letters layers of the smaller cations. Manganous telluride appears to be very nearly stoichiometric, ${ }^{1}$ although Johansen ${ }^{2}$ reported that MnTe has an excess of $\mathrm{Te}$ with a homogeneity range $\mathrm{MnTe}_{1.002}$ to $\mathrm{MnTe}_{1.013}$. Panson and Johnston ${ }^{3}$ found that in the system MnSe-MnTe below $500^{\circ} \mathrm{C} 13$ at.\% Te could be substituted for Se in the MnSe lattice and that about 20 at.\% of the Te could be replaced by Se in the MnTe lattice. Manganous telluride transforms to the $\mathrm{NaCl}$-type structure above $1040^{\circ} \mathrm{C}$ and melts

Received March 12, 1969; revised copy received October 13 , 1969.

Based on a thesis submitted by Paul G. Riewald for the Ph.D. degree at The University of Michigan.

*Now with the Pioneering Research Laboratory, Textile Fibers Department, E. I. du Pont de Nemours \& Co., Wilming ton, Del. 19898. 
at about $1170^{\circ} \mathrm{C} .{ }^{3}$ It also undergoes an antiferromagnetic transformation on cooling below $310^{\circ} \mathrm{K}$ which results in a sharp contraction of the c axis.,

Moore $^{6}$ found that the primary deformation mechanism in MnO is slip in $\langle\overline{1} 10\rangle$ directions on $\{110\}$ planes, which is the usual mechanism in NaCl-type ionic crystals. " Chao et al. ${ }^{3}$ also found that the $\{110\}<1 \overline{1} 0\rangle$ mechanism was primary in MnS but detected secondary glide on $\{111\}$ planes. Manganous selenide has $\{111\}<\overline{10}\rangle$ and $\{111\}<\overline{110}>$ as the primary and secondary slip mechanisms, respectively., ${ }^{9,10}$ The change in primary mechanism in $\mathrm{MnSe}$ is related to a decrease in the ionic character of the chemical bond with increased anion size. ${ }^{9,11}$

Fracture in $\mathrm{MnO},{ }^{6} \mathrm{MnS},{ }^{8}$ and $\mathrm{MnSe}^{9,10}$ is characterized by easy $\{100\}$ cleavage and secondary $\{110\}$ fracture. Around Vickers microhardness indentations, MnS showed primarily $\{110\}$ fracture because of multiple slip interactions on adjacent $\{101\}$ slip planes, ${ }^{8}$ whereas interactions on $\{111\}$ slip planes in MnSe produced $\{100\}$ fracture. ${ }^{9,10}$

\section{Experimental Procedure}

\section{(1) Preparation and Purification of Raw Materials}

Manganous telluride and selenide were prepared from $\mathrm{Mn}$ powder made from triply vacuum-distilled electrolytic Mn and from Te or Se powder prepared from high-purity shot. The powders were mixed in appropriate proportions, placed in a vacuum-degassed graphite crucible, encapsulated in a borosilicate glass tube under vacuum, and reacted at $600^{\circ} \mathrm{C}$ for several days. Both $\mathrm{MnTe}$ and MnSe were purified further by zone refining. ${ }^{9}$

Microscopy revealed no other phases except an occasional small inclusion which was apparently $\mathrm{MnO}$. X-ray data gave lattice parameters for MnTe of $a_{0}=4.138$ and $c_{0}=6.706 \AA$; average values of $a_{0}=4.137$ and $c_{0}=6.706 \AA$ were reported in the literature by ten independent workers. The lattice parameter for MnSe was $a_{0}=5.463 \AA ; 5.462 \AA$ is the accepted value. ${ }^{\text {.1 }}$

Chemical analyses of MnTe gave $30.2 \pm 0.3 \%$ Mn compared with $30.1 \% \mathrm{Mn}$ for stoichiometry. For MnSe, analyses gave $40.8 \pm 0.4 \%$ Mn compared with $41.0 \%$ for stoichiometry.

\section{(2) Crystal Preparation}

Single crystals of MnTe, MnSe, and appropriate MnSe-MnTe compositions were prepared by a Bridgeman technique. ${ }^{9}$ The growth of high-quality single crystals of MnTe was difficult because of the polymorphic phase change at $1040^{\circ} \mathrm{C}^{3}$ and the $c$ axis contraction at $310^{\circ} \mathrm{K}$ caused by the antiferromagnetic transformation., ${ }^{4,5}$ Usually a coarse-grained structure was obtained in which individual grains tended to be misoriented by up to $8^{\circ}$ to $10^{\circ}$. This structure was a coarse mosaic in which all the mosaic parts were within $\pm 5^{\circ}$ of an average orientation. Often a "crystal" would show only two or three orientations differing by not more than $\pm 3^{\circ}$ from a mean value; these crystals were used whenever possible.

Single crystals were annealed for $12 \mathrm{~h}$ at $1000^{\circ} \mathrm{C}$, oriented by the Laue back-reflection technique, and cut to reveal selected faces. For cubic crystals, (001), (011), and (111) planes were studied, whereas for hexagonal crystals (0001), $(10 \overline{1} 0)$, and $(11 \overline{20})$ planes were selected. Cubic orientations were accurate to within $2^{\circ}$ and hexagonal orientations to within about $8^{\circ}$ to $10^{\circ}$.

Samples were mounted in Bakelite and mechanically polished using standard metallographic techniques. Care was taken during the latter stages of polishing to remove chemically any disturbed surface layers with an etchant of $1 \%$ $\mathrm{H}_{3} \mathrm{SO}_{4}, 1 \% \mathrm{H}_{3} \mathrm{PO}_{4}$, and $1 \%$ saturated oxalic acid solution. Subsequent Laue photographs showed no significant residual plastic deformation in the crystals.

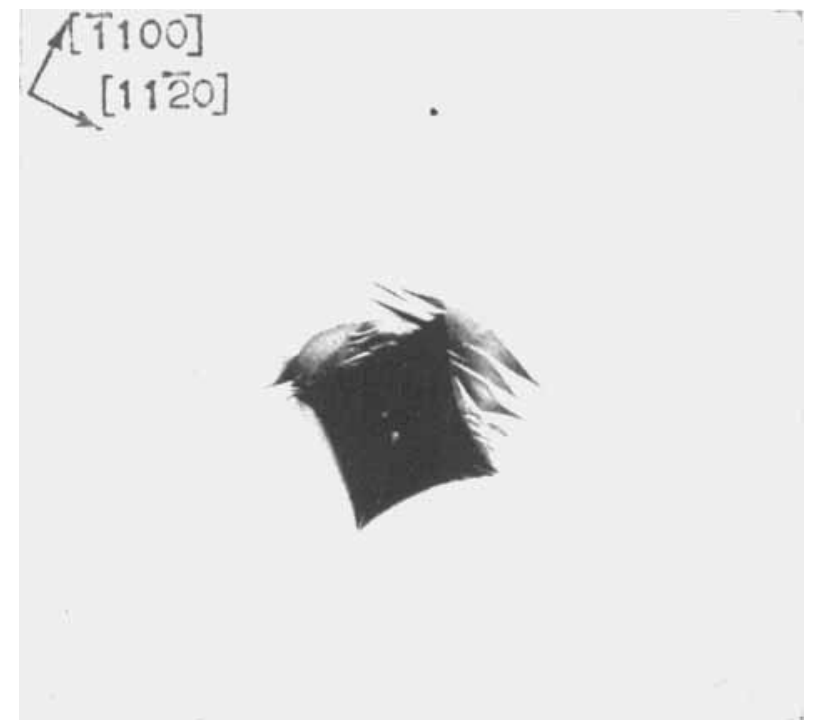

Fig. 1. Vickers hardness impression on (0001) surface of MnTe crystal showing traces due to $\{10 \overline{1} 2\}$ twinning $(\times \mathbf{2 5 0})$.

\section{(3) Testing and Examination}

Samples were indented with either a Vickers or a Knoop diamond, and the hardness was measured. The long axis of the Knoop indenter was made parallel to the several low index crystallographic directions on each of the planes tested.

Microscopy under obliquely reflected light revealed slip traces around the indentations. From the orientations of these patterns on each of the crystal surfaces, stereographic projections could be plotted, and the plane or planes on which slip occurred could be determined. ${ }^{12}$

Fracture was studied by inducing cleavage on several of the crystal planes and by observing fracture in crushed fragments. Fracture planes were verified by the Laue X-ray back-reflection technique. Also, any fracturing around indentations was related to slip interactions.

\section{Results and Discussion}

\section{(1) Manganous Telluride}

(A) Plastic Deformation: The modes of plastic deformation identified in MnTe were twinning on $\{10 \hat{1} 2\}$ planes, slip involving the $(0001)$ plane, and pencil glide with $\langle 1 \overline{12} 0\rangle$ as the zone axis. The preferred mode varies with the exposed crystal plane and the stress direction.

Indentation into the basal plane produced patterns (Fig. 1) which may be attributed to $\{10 \overline{1} 2\}$ twinning. The twin traces appear in two of the three possible $\langle 1 \overline{12} 0\rangle$ intersection directions involving $\{10 \overline{1} 2\}$ planes. (The activation of the twinning on only one side of the indenter reflects the previously explained slight misorientation of the (0001) plane.) Interferometry showed that this displaced material was raised. This result further supports the twinning mechanism since, with $c / a<\sqrt{3},\{10 \overrightarrow{12}\}$ twinning produces an elongation in the [0001] direction. Partridge and Roberts ${ }^{13}$ reported similar results in $\mathrm{Mg}$ single crystals which they identified as $\{10 \overline{12}\}$ $<1011>$ twinning.

When either the $\{11 \overline{2} 0\}$ or the $\{10 \overline{10} 0\}$ surface was indented with the indenter perpendicular to [0001], slip traces appeared perpendicular to [0001] (Figs. 2 and $3(A)$ ). Movements on the basal, or (0001), plane must be present to account for both of these observations. However, each set of slip traces 


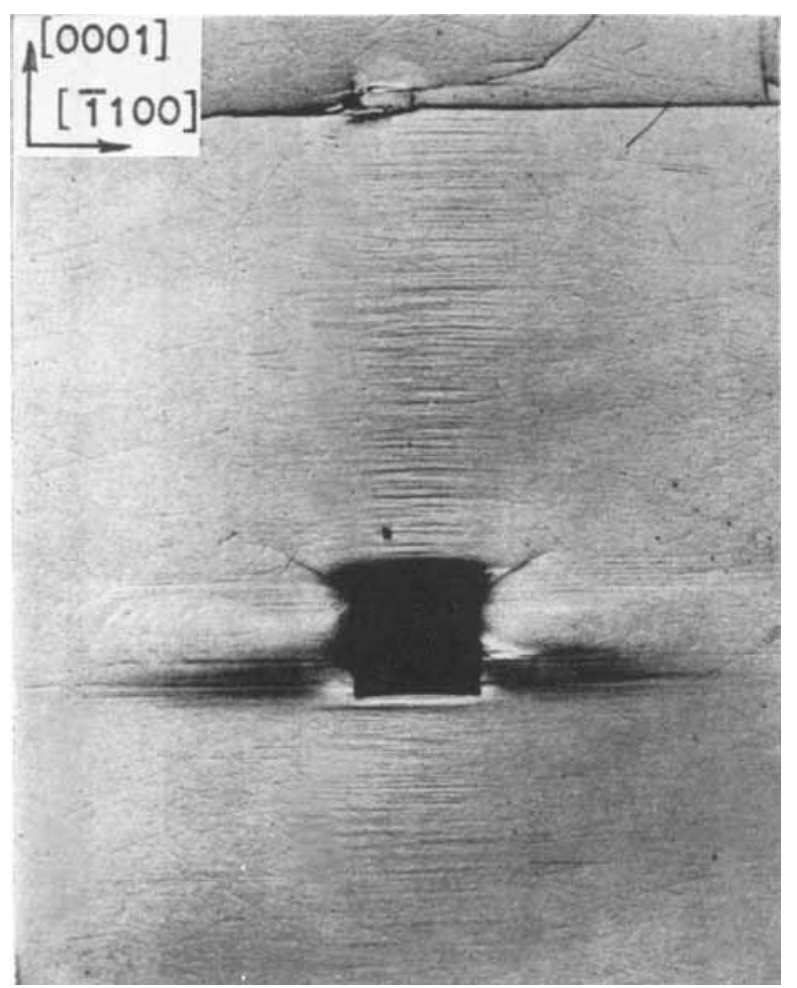

Fig. 2. Vickers hardness impression on (11) 0 ) surface of MnTe crystal showing (0001) cleavage crack and slip traces due to $(0001)$ slip and pencil glide $(\times 150)$.

must also include movement with a [0001] vector to produce the total deformation. The planes which contain the latter displacement were not identified.

Figure $3(B)$ reveals wavy slip lines which must be attributed to many slip systems deforming simultaneously. This behavior suggests pencil glide, and since the $\langle 11 \overline{2} 0\rangle$ Burgers vector has the shortest displacement distance, that possibility may be examined on a stereographic projection (Fig. 4). As shown on the $(10 \overline{1} 0)$ projection, there are many possible planes within the common [11 20$]$ zone axis (and within the [2110] zone axis). These intersect the (1010) plane at a variety of angles, as is observed in Fig. $3(B)$. The same wavy deformation pattern is faintly visible on the (1120) surface to the left of the indenter in Fig. 2. Again pencil glide

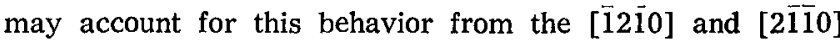
zones; however, with a steeper angle, the amount of slip should be less. This type of deformation may also be described as extensive cross-slip and is common for many materials, e.g. $\mathrm{AgCl},{ }^{7} \mathrm{AgBr},{ }^{8} \alpha-\mathrm{Fe},{ }^{12}$ and $\mathrm{Hg},{ }^{12}$ all of which, like $\mathrm{MnTe}$, are soft with easy dislocation movements.

(B) Fracture: The primary cleavage plane for MnTe appears in Fig. 2 and is $\{0001\}$; this plane reveals bright shiny surfaces. $A\{10 \overline{1} 0\}$ cleavage was also observed and it exposed a rather dull surface. Furthermore, pyramidal cleavage was found in some specimens around inclusions (Fig. 5). Evidently a moving (0001) cleavage crack meeting a foreign particle finds it energetically easier to move over and around some of the inclusions rather than through them.

\section{(2) MnSe-MnTe System (MnTe-Rich Portion)}

(A) Plastic Deformation and Fracture: Within the MnTerich single-phase region of the MnSe-MnTe system, samples of 9 and 19 at.\% MnSe were studied. Both showed the same modes of plastic deformation found in pure MnTe: $\{10 \overline{1} 2\}$ twinning, basal slip, and pencil glide in $\langle 11 \overline{2} 0\rangle$. Fracture
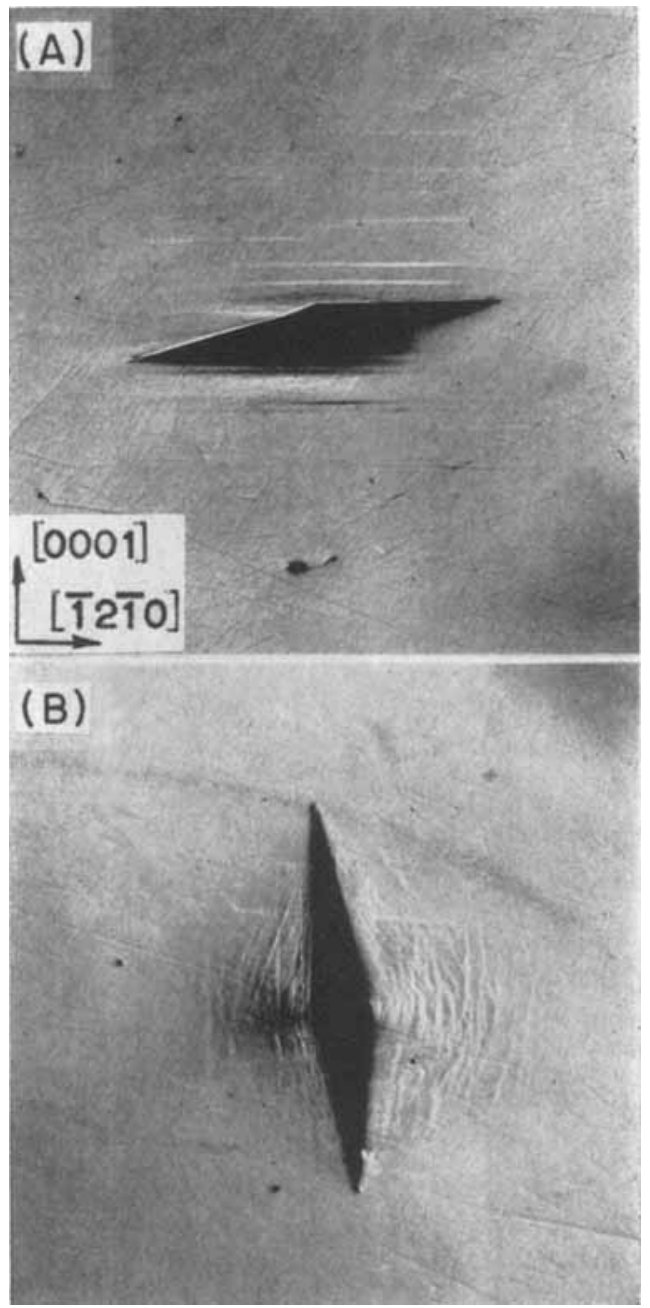

Fig. 3. Knoop hardness impression on (10̄̄o) plane of MnTe erystal for two indenter orientations showing $(A)$ basal slip and $(B)$ wavy slip lines characteristic of pencil glide $(\times 250)$.

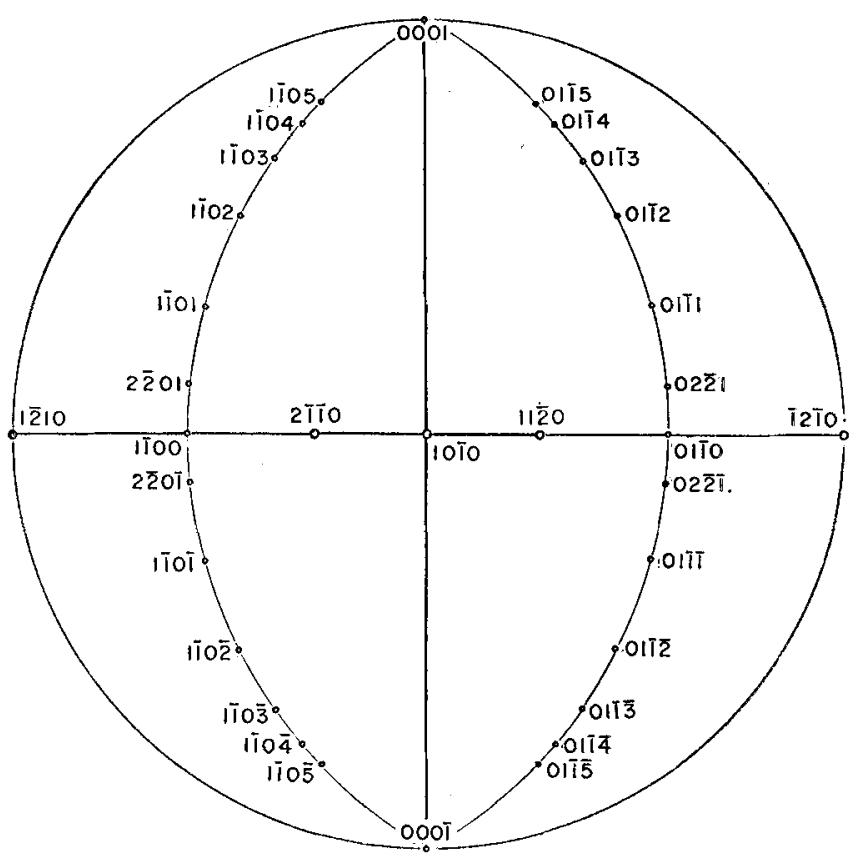

Fig. 4. A (1010) stereographic projection for MnTe showing families of planes having $\langle 11 \overline{2} 0\rangle$ direction as zone axis. 


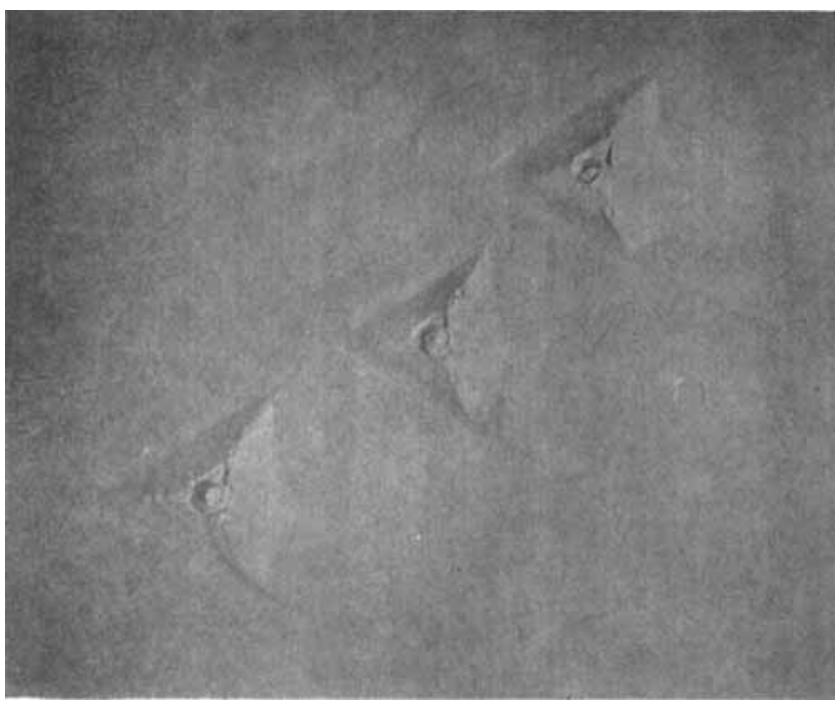

Fig. 5. Pyramidal cleavage around inclusions on (0001) primary cleavage plane of MnTe single crystal $(\times 10,500)$.

mechanisms were also the same as those in pure MnTe: $\{0001\}$ and $\{1010\}$ cleavage.

(B) Diamond Pyramid Hardness: Figure 6 shows the $\mathrm{DPH}$ results for the MnTe-rich solutions. The DPH on the basal plane was about $60 \%$ greater than that on (10 $\overline{10}$ ) for all compositions. The higher hardness of the basal plane reflects the difficulty of activating slip systems capable of moving material to the surface to make room for the indenter; this cannot be done by glide in $\langle 1 \overline{12} 0\rangle$ directions alone because they are all parallel to the (0001) plane.

(C) Knoop Hardness: Figure 7 shows the Knoop hardness results for these solutions. As with other single crystal specimens, ${ }^{9.13}$ Knoop hardness on the $\{10 \overline{10}\}$ planes showed an anisotropy which depended on the orientation of the long axis of the indenter and the symmetry of the slip systems of the crystal, All orientations of the indenter on the basal plane, however, gave the same hardness within the $\pm 4 \%$ limits of experimental error, but, as with Vickers hardness, the basal plane was much harder than the $(10 \overline{10})$ plane. The variation on the $(10 \overline{10})$ plane reflects the many slip systems which can be activated during pencil glide for the [0001] indenter orientation but which cannot be supplied by the predominantly basal slip found at the $[\overrightarrow{1} 2 \overrightarrow{1} 0]$ indenter orientation (Fig. 3 ).

Similar tests on the $(1 \overline{12} 0)$ plane gave results virtually identical to those found on $(10 \overline{10})$.

\section{(3) MnSe-MnTe System (MnSe-Rich Portion)}

(A) Plastic Deformation and Fracture: Sodium chloridetype MnSe has $\{111\}<1 \overline{10}>$ and $\{110\}<1 \overline{10}>$ as primary and secondary slip mechanisms, respectively. ${ }^{10}$ Within the cubic single-phase region, the compositions studied were 93 at.\% MnSe-7 at.\% MnTe and 87 at.\% MnSe-13 at.\% MnTe. Both compositions showed slip traces due to $\{111\}<1 \overline{1} 0>$ and $\{110\}<1 \overline{1} 0>$ glide, with the amount of $\{110\}$ glide somewhat more extensive than for comparable substitutions of sulfide for selenide ions. Figure 8 shows slip traces due to both slip mechanisms on the (001) plane of a $93 \mathrm{MnSe}-7 \mathrm{MnTe}$ crystal. The $\{110\}$ slip traces form a square arrangement in $\langle 100\rangle$ directions, whereas the fainter $\{111\}$ traces are at $45^{\circ}$ to $\langle 100\rangle$ directions. Similar indentations on the (011) and (111) planes confirmed these findings.

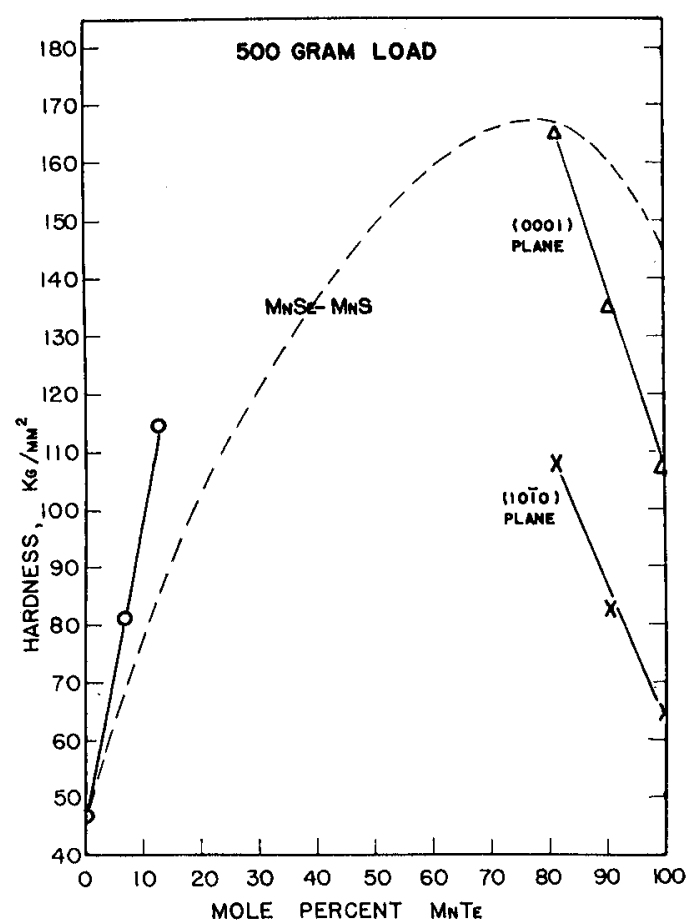

Fig. 6. Diamond pyramid hardness for MnSe-Mn'Te solid solutions with results for the MnSe-MnS system added for reference.

As with pure MnSe, both of these solid solutions showed primary $\{100\}$ and secondary $\{110\}$ cleavage in crushed fragments. ${ }^{10}$ In contrast, increased MnTe contents increased the relative incidence of $\{110\}_{90^{\circ}}$ fractures around (001) surface

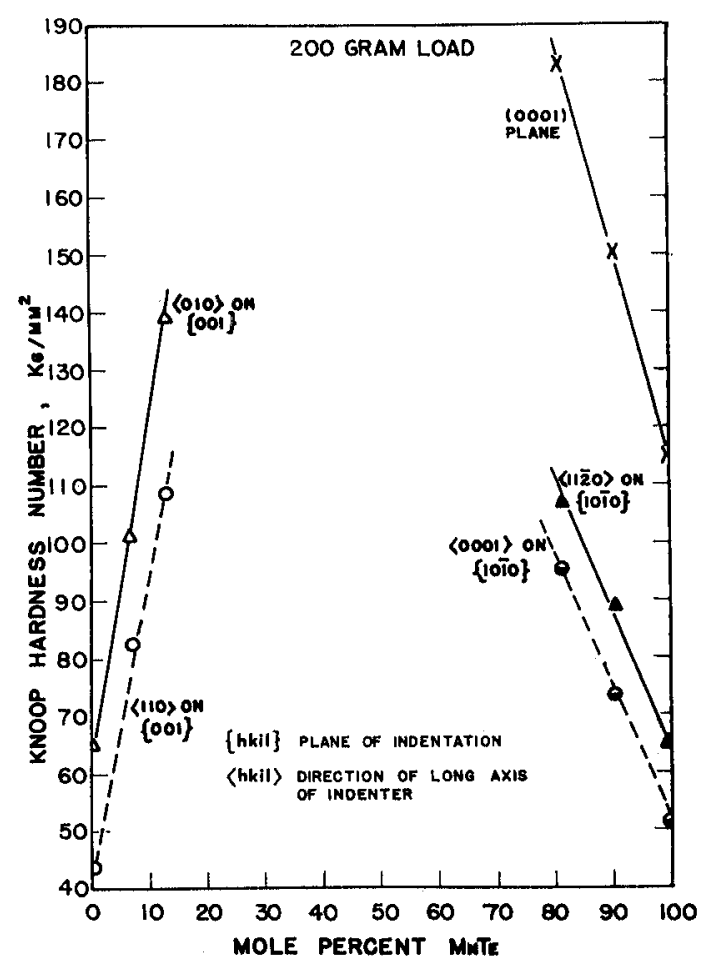

Fig. 7. Knoop hardness for MnSe-MnTe solid solutions. 


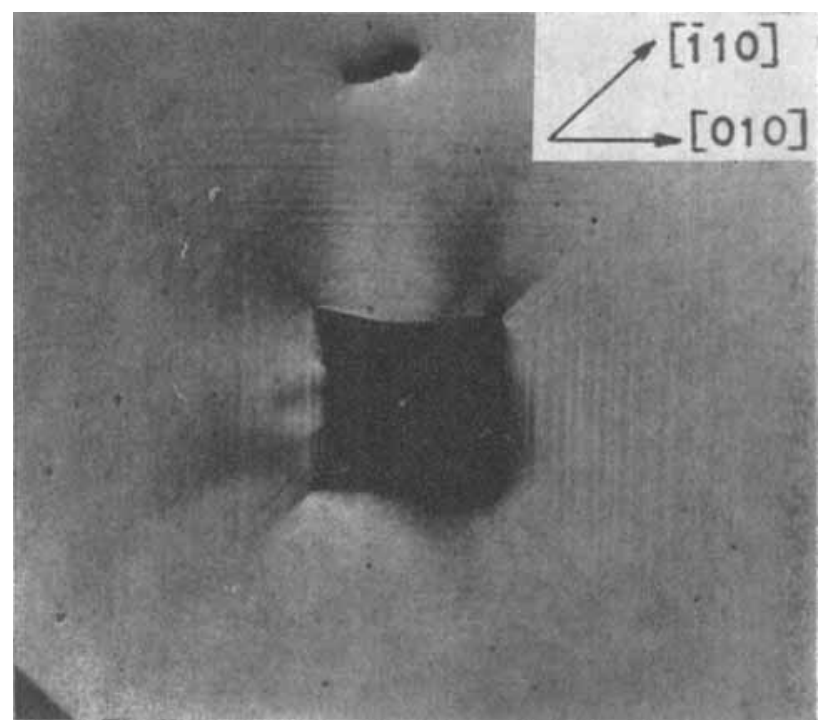

Fig. 8. Slip traces around Vickers indentation on (001) surface of $93 \mathrm{MnSe}-7 \mathrm{MnTe}$ crystal showing $\{110\}$ and (111\} slip (oblique lighting; $\times 250$ ).

indentations and decreased the relative incidence of $\{100\}_{00^{\circ}}$ fractures. The $\{110\}_{m}$ fracture is a consequence of dislocation interactions on intersecting $\{110\}_{45^{\circ}}$ slip planes, ${ }^{8}$ whereas the $\{100\}_{m}$ fracture stems from dislocation interactions on adjacent $\{111\}$ slip planes., to

(B) Diamond Pyramid Hardness: Although the Vickers hardness was essentially the same on the $\{001\},\{011\}$, and \{111\} planes, the values were higher than those observed for comparable substitutions of sulfide for selenide ions (dashed lines in Fig. 6). The difference in ionic radii between $\mathrm{S}^{2-}$ and $\mathrm{Se}^{2 \cdots}$ ( 1.74 vs $1.91 \AA$, Goldschmidt) is $8.9 \%$, whereas that between $\mathrm{Te}^{2-}$ and $\mathrm{Se}^{2--}$ (2.11 vs $1.91 \AA$ ) is about $10.5 \%$. Although the bonding is not totally ionic, and ionic radii, therefore, are not strictly applicable, this comparison indicates that a slightly larger size mismatch in the case of the telluride may cause the observed higher rate of hardening.

(C) Knoop Hardness: The Knoop hardness results for both compositions followed the same pattern as for pure MnSe; that is, for indentations on the (001) plane, the hardness was lowest when the long axis of the indenter was parallel to $\langle 110\rangle$ (Fig. 7). Also, like the Vickers hardness results, the rate of hardening was greater than that found for the substitution of sulfide for selenide ions. Similar results were found on the (011) plane.

\section{Conclusions}

(1) Manganous telluride shows patterns consistent with three modes of plastic deformation around Vickers and Knoop indentations: $\{10 \overline{1} 2\}$ twinning, basal slip, and pencil glide in $<11 \overline{2} 0\rangle$.

(2) Fracture in MnTe occurs as primary $\{0001\}$ and secondary $\{10 \overline{10}\}$ cleavage both in crushed fragments and around surface indentations. Pyramidal cleavage can also occur, especially around small inclusions.

(3) Solid solutions formed by substitution of selenide ions in the MnTe matrix show the same plastic deformation and fracture characteristics as MnTe. The basal plane is harder than the prism planes, reflecting the difficulty of activating enough independent slip systems by basal indentation.

(4) The addition of telluride ions to MnSe results in an early appearance of $\{110\}$ slip and produces a slightly higher rate of solid-solution hardening than a comparable substitution of sulfide ions.

\section{References \\ ${ }^{1}$ S. Furberg, "System Mn-Te," Acta Chem. Scand., 7 [4] 693- 94 (1953).}

${ }^{2}$ H. A. Johansen, "Stoichiometry of MnTe," J. Inorg. Nucl. Chem., 6 [4] 344-45 (1958).

A. J. Panson and W. D. Johnston, "MnTe-MnSe System," ibid., 25 [5] 701-93 (1964).

${ }^{4} \mathrm{~S}$. Greenwald, "Antiferromagnetic Structure Deformation in CoO and MnTe," Acta Crystallogr., 6 [5] 396-98 (1953).

${ }^{5}$ N. P. Grazhdankina and D. I. Gurfel, "X-Ray Diffraction Study of the Thermal Expansion of Antiferromagnetic MnTe," Sov. Phys. JETP, 35 [4] 907-10 (1958).

' J. W. Moore, "Structure and Properties of Oriented Compound Eutectics"; Ph.D. Thesis, University of Michigan, 1965; Univ. Microfilms (Ann Arbor, Mich.), Order No. 66-6659, 168 pp.; Diss. Abstr., 26 [12] 7243-44 (1966).

'J. J. Gilman; pp. 146-99 in Progress in Ceramic Science, Vol. 1. Edited by J. E. Burke. Pergamon Press, New York, 1961 .

${ }^{8}$ H. C. Chao, L. Thomassen, and L. H. Van Vlack, "Deformation and Fracture of MnS Crystals," ASM Trans. Quart., 57 [2] 386-98 (1964).

${ }^{9}$ P. G. Riewald, "Deformation, Fracture and Hardness Characteristics of Compounds of Manganese with Group VI Elements"; Ph.D. Thesis, University of Michigan, 1968.

${ }^{10}$ P. G. Riewald and L. H. Van Vlack, "Slip Behavior and Hardness Indentations in MnSe and MnSe-MnS Solid Solutions," $J$. Amer. Ceram. Soc., 52 [7] 370-75 (1969).

${ }_{11}$ ASTM X-Ray Powder Diffraction Data File, Card No. 11683. American Society for Testing and Materials, Philadelphia, $\mathrm{Pa}$.

${ }_{12}$ C. S. Barrett, Structure of Metals, 2d ed. McGraw-Hill Book Co., New York, 1952.

${ }^{13}$ P. G. Partridge and E. Roberts, "Microhardness Anisotropy of Magnesium and Zinc Single Crystals," J. Inst. Metals, 92 [2] 50-55 (1963-64).

\section{Discussions and Notes}

\section{Comments on "Wetting of Binary Aluminum Alloys in Contact with $\mathrm{Be}, \mathrm{B}_{4} \mathrm{C}$, and Graphite",}

\section{J. G. EBERHART}

$\mathrm{R}$ ECENTLY Manning and Gurganus? reported measurements of the wettability of solid $\mathrm{Be}, \mathrm{B}_{4} \mathrm{C}$, and graphite with various liquid alloys of Al. Some comments on their interpretation of these measurements are offered.
Received October 8, 1969; revised copy received November 19, 1969.

The writer is with the Chemical Engineering Division, Argonne National Laboratory, Argonne, Illinois 60439. 